\title{
JUGANDO A HACER UNA PELÍCULA
}

Criticidad y Creatividad ${ }^{*}$

Una experiencia de CEFOCINE

- Centro de Formación Cinematográfica

para Niños-

Carmita Coronado

Docente de la Universidad Politécnica Salesiana

Fundadora de CEFOCINE

\section{Preámbulo}

Cuantas veces pensemos en el hombre, tenemos que pensar en el trabajo. Nuestras manos, que son capaces de realizar las labores más delicadas con destreza y habilidad sin igual en el reino animal, son obras del trabajo. El conocimiento cada vez más perfecto del mundo que nos rodea se debe al trabajo.

El hombre en un comienzo se servía de la naturaleza, de aquello que le brindaba el medio, pero sin hacer uso de ningún intermediario. Entre el fruto, la semilla y la necesidad de alimento, sólo se interponía la mano.

* La autora es Master en Investigación y Docencia de la Comunicación. PUCE. Quito. 
Las necesidades van desarrollando la capacidad de elaborar instrumentos. El ser humano primero los tomó de la naturaleza, luego los sometió a un largo proceso de transformación y produjo objetos verdaderamente nuevos. Transcurrió un largo período en el cual no sólo se perfeccionaron los instrumentos usados por el hombre, sino también el hombre mismo. Cuando el hombre llegó a concebir instrumentos que no eran ya producto de una selección, sino creación enteramente humana, se completó este proceso de experimentación. Existe una interrelación entre el hombre y el medio, un proceso incesante de intercambios, gracias al cual vive, se supera y domina la naturaleza.

El hombre al elaborar instrumentos para trabajar, se inició como creador, capacidad que fue ganando independencia con el pasar del tiempo. A los primeros instrumentos, no tomados ni copiados de la naturaleza sino concebidos con aditamentos, fruto de un largo período de experimentación, le sucedieron otros implementos que, además del valor funcional que poseían, presentaban dibujos o incisiones en apariencia carentes de utilidad. En la práctica, estos signos estaban ligados al proceso productivo y, con ellos también, el hombre reafirmaba su ser creador, su naturaleza de productor.

$\mathrm{Si}$ en un comienzo esos trazos sobre piedra o hueso traducían inconscientemente el ritmo del trabajo, más tarde se convirtieron en señales conscientes de su potencia creadora, del reconocimiento de su existencia y su fuerza. La utilidad de esos instrumentos ya no sólo era en la práctica, sino en el campo de las ideas. Se había originado el objeto útil-bello. El arte surge, de esta manera, como fruto desarrollado del trabajo.

Hablar de arte, según el diccionario, es el... 
- Ejercicio de las facultades humanas preparado por experiencias anteriores;

- Conjunto de normas y preceptos acumulados por generaciones anteriores en una actividad;

- Aptitud individual, disposición para hacer una cosa.

Son muchas las teorías acerca del arte: unas destacan el componente lúdico, no utilitario (Schiller, Freud, Marcuse); otras dan mayor valor a su función social de comunicación.

También se ha considerado dentro de la semió-

tica general o ciencia de los signos; con esta teoría, la forma se ha querido separar del contenido; ambos siempre se encuentran unidos por una interacción dialéctica, ya que el contenido no es solamente lo que se representa, sino cómo se representa. La historiografía del arte consideró en un principio que las formas y los estilos eran autónomos respecto a cualquier otra consideración; hoy lo relaciona con el desarrollo general de la cultura.

Un aporte nuevo a la definición de arte: "Acto o facultad mediante el cual, valiéndose de la materia, de la imagen o del sonido, el hombre imita o expresa lo material o lo inmaterial, y crea copiando o fantaseando".

\section{Arqueología del cine}

En el abanico de las artes está una que, desde su nacimiento, revolucionó la sociedad. Me refiero al cine: los hermanos Lumiere no dimensionaron el real impacto de su invento; 1895 marca para la historia de la humanidad un antes y un después de esa primera experiencia de la imagen en movimiento: "la llegada del tren" que conmociona al público que corre despavorido "ante la sensa- 
ción de que el tren se les viene encima". Las relaciones humanas, económicas, sociales y, por supuesto, educativas, se ven afectadas por este descubrimiento que, como sus inventos previos, llevaba a percibir la realidad desde otra realidad creada, imitada, copiada.

La imagen en movimiento - que es lo que significa el cine- incorpora cada vez más otros recursos, efectos especiales y una serie de elementos que exigen del espectador el manejo de nuevos códigos y lenguajes que, sin tener que atravesar el proceso largo y complejo del lenguaje oral o escrito, obligan a conocer significados propios, dados desde el manejo de los mismos al ofertar "historias, dramas, acción, fantasías, etcétera", ayudados por la renovada tecnología que, puesta a su servicio, es el espacio ideal donde se conjugan: danza, teatro, expresión corporal, música, decoración, vestuario, ambientación $y$, claro está, actuación, personajes interpretados y asumidos por hombres y mujeres. Todo esto, orquestado por un director que, acompañado de un equipo humano especializado en cada elemento, hace del medio cinematográfico una clara manifestación de arte: el cine como arte.

En la actualidad hacer cine tiene el auxilio de una cantidad de ayudas; por ejemplo, la informática, que le permite mostrar lo que en sus inicios era una verdadera odisea, me refiero a los efectos especiales.

\section{2. ¿Cómo entender al cine en su dimensión motivadora del desarrollo del pensamiento en el proceso educativo?}

Vivimos en un mundo de imágenes producidas por la tecnología que, de una u otra manera, expresan "el mundo de imágenes que llevamos dentro", en unos casos $y$, en otros, que "entran desde las otras realidades" fanta- 
siosas y hasta inverosímiles que tocan las fibras afectivas de los seres humanos en cualquier etapa de su desarrollo.

¿Qué respuesta dar o qué actitud tomar ante esa avalancha icónica?

Si educar es humanizar, esto es, hacer y hacerse íntegramente persona, hay que aprender el lenguaje, el arte, la moral, la ciencia, y es ahí donde entra este medio; si filosofar es preguntar, criticar, reflexionar, desenmascarar, crear problemas, ¿qué mejor motivación que una historia cinematográfica para ejercitar estas capacidades humanas?

\section{Educar por y con imágenes en movimiento}

Para entrar en este ámbito, lo mejor es contextualizarlo desde las características de la imagen visual; entre las más importantes:

- Figuración de una imagen: idea de representación de objetos o seres conocidos.

- Grado de iconicidad: como opuesto al grado de abstracción y que hace referencia a la calidad de la identidad de la representación con el objeto representado.

- Grado de complejidad: el número de elementos que la conforman así como las competencias del espectador.

- El tamaño: grado de ocupación del grado visual.

- Los grosores de la toma, las distintas cualidades técnicas, contrastes, iluminación, nitidez, etcétera.

- La presencia o ausencia del color, la dimensión estética, la dispersión del sentido.

- El grado de normalización, copiados múltiples y difusión masiva. 
La invasión icónica combinada con su carácter predominantemente realista es la que ha provocado el equívoco que sostiene que las imágenes comunican en forma directa, pasando por alto la necesidad de analizar cómo comunican y funcionan los discursos visuales, evitando la proliferación de esa especie contemporánea llamada el ciego vidente.

Otro aspecto digno de ser tomado en cuenta son los valores de la imagen: la imagen es la madre del signo, pero el nacimiento del signo escriturístico permite a la imagen vivir plenamente su vida de adulto, separada de la palabra y liberada de sus tareas triviales de comunicación.

El signo nos conduce al conocimiento de otra cosa que está oculta, nos hace llegar al conocimiento de lo desconocido mediante lo que es conocido. San Agustín define al signo como aquello que introduce una imagen en los sentidos, y nos lleva al conocimiento de otra cosa.

La teoría tomista diferencia el signo de la imagen, argumentando que las que dan significado al signo son las personas, mientras que las imágenes son producidas por el mismo objeto; además, la función del signo es ser intermediario, mientras que la imagen es representación directa del objeto.

La imagen adquiere significación por el juego dialéctico entre productor y observador; una imagen no significa nada por sí misma, necesita la interpretación del perceptor; una imagen es una forma vacía y necesita de la competencia interpretativa de un observador, se necesita que la imagen sea llenada de contenidos, de experiencias.

Es necesario aprender a leer las imágenes, sobre todo ahora que vivimos en un mundo de imágenes visuales artificiales, en donde lo que se percibe no es la realidad; necesitamos conocer y analizar los sentidos que el emisor quiere trasmitirnos a través de sus imágenes. La impor- 
tancia de conocer el significado real de las imágenes visuales también radica en la gran credibilidad que el hombre contemporáneo da a éstas.

No sólo las palabras son signos; es necesario recordar que existen innumerables sistemas de significación, de comunicación no verbales que, en la actualidad, han cobrado un inusitado desarrollo e importancia cualitativa y cuantitativa.

Hoy la imagen parece dejarse juzgar sólo local o comparativamente: pide ser afrontada desde un punto de vista moral, estético, político, etcétera, ya que es una realización individual o representante de un género, no una simple imagen. En otras palabras, más allá de algún ejemplo de optimismo modal, o más allá de un ejemplo igualmente modal, el universo de la imagen no parece hoy plantear una propia axiología definida y unívoca.

Varios autores han intentado definir un valorimagen:

- Bazín: veía en la imagen el esfuerzo de hacer frente a la muerte, y en la imagen fotográfica, la posibilidad de recuperar la esencia del mundo.

- Mitry: para él la imagen era el punto de encuentro de concreción y abstracción o de contingencia y de necesidad.

- Llyotard: advertía en la imagen el dominio de lo energético y de lo pulsional.

Hoy la imagen se presta a tener valores, pero no constituye de por sí un valor -signo; surgen posiciones que sin pretender tocar la totalidad de la imagen tratan de leer su desarrollo de conjunto, así:

- La primera posición es la que propone la imagen-nada; el destino de la imagen en nuestra 
época no diverge de la de cualquier objeto artístico, asume la categoría de mercancía, de bien cultural, llamado a responder las necesidades de diversión y distracción; se vuelve una instrucción para el consumo. De hecho, el frente avanzado de la industria cultural está representado por la industria de la imagen: antes el cine, hoy la televisión.

- La segunda posición, la imagen-trampa; la imagen de hoy, tal como se presenta sobre todo en la fotografía, el cine y la televisión, es heredera de la perspectiva central, el sujeto tiene la ilusión de dominar plenamente el mundo representado.

- La tercera posición, una imagen-cuerpo; Roland Barthes es el autor que más ha trabajado en ella; la imagen es un soporte físico, el lugar de inscripción, el ámbito de un trabajo. Los materiales que le dan cuerpo, su textura concreta, nos abren un sentido concreto que está bajo el esplendor de lo representado, y el cuerpo del observador; sólo cuando una reacción personal enciende la imagen y lleva a pinchar, esta funciona de verdad. Entonces, es una participación emotiva, un acercamiento, una bajada a los adornos visibles, lo que da espesor al juego.

- La cuarta posición, la imagen-capital; la imagen contemporánea no vale simplemente por lo que exhibe, sino por su capacidad de recuperarse y fundir lo que constituye el fondo de nuestra cultura.

- La quinta posición propone una imagen-todo; es una elaboración de filósofos (sobre todo interesados en el cine, como Delenze) con una hipótesis de fondo: que la imagen contemporánea 
nos ponga en contacto con la globalidad de lo real. La imagen a través de una especie de implosión nos exhibe más que una vista el horizonte mismo del ver. (Giovanni Anceshi, Video culturas del fin de siglo).

La palabra es el conjunto de sonidos organizados que corresponden a unas imágenes mentales, verbales, sensitivas que se almacenan al interior del cerebro y pueden ser utilizadas para expresar mensajes preconcebidos.

En la era de la imagen y la tecnología, ¿qué valor tiene la imagen? El valor se da desde la emisión y se configura desde el perceptor.

\section{El papel de la educación de la percepción}

La imagen es hoy una base fundamental sobre la que se apuntalan las estrategias imperativas de los medios de comunicación social; para su concreción exige:

- Unos emisores individuales o centralizados (red de televisión, distribuidora cinematográfica, agencia de publicidad...).

- Unos canales de televisión caracterizados por su elevada tecnología.

- Unos receptores que constituyen un círculo indefinido de individuos con diferencias socioculturales.

La percepción equivale al poder de organizar la información visual que se percibe, la que depende de mecanismos naturales, de las necesidades y propensiones del sistema nervioso humano. Aunque los franceses dominan la psicología de la Gestal, sería erróneo no con- 
ceder idéntica importancia a la filosofía de la percepción en el examen de cómo extraemos información visual de lo que vemos. El contenido y la forma es la declaración; el mecanismo de percepción es el medio para su interpretación. El imput visual se ve muy afectado por el tipo de necesidades que motivan la investigación visual, así como por el estado mental o de ánimo del sujeto.

La inteligencia no actúa sólo en las abstracciones verbales; el pensamiento, la observación, la comprensión y otras tantas cualidades de la inteligencia están ligadas al entendimiento visual. Pero el pensamiento visual no es un sistema retardado; la información se transmite directamente. El mayor poder del lenguaje visual radica en su inmediatez, en su evidencia espontánea. Ver es un hecho natural del organismo humano; la percepción es un proceso de capacitación.

Lo importante es saber qué concepción tiene el receptor (perceptor) de tal o cual categoría de programa, ahí la explicación de su afición. Como dice Roger Silvestrone en su obra Tv y Vida Cotidiana: "los individuos construyen los sentidos de los textos y las interpretaciones de los personajes, las acciones, las motivaciones y la narrativa como conjunto traducido a sus propios términos, esto es, ajustado a sus propios sistemas de creencias".

La esencia de la percepción estaría en la transformación de la impresión sensitiva (sensación) en información cognitiva.

La percepción se concibe como una dialéctica entre sujeto y realidad, entre las propiedades de los objetos y la naturaleza e intenciones del observador. Por eso se habla de percepción como modificación de una anticipación y de un proceso activo-selectivo que depende de las estrategias cognitivas (atención del observador, intenciones perceptivas) puestas en juego ante la realidad. 
Furio Colombo hace notar de un modo pertinente que, hoy, la absorción de mensajes audiovisuales es tan grande que muchas veces no sabemos a ciencia cierta si una experiencia la hemos vivido o la hemos visto en la pantalla del televisor.

Siendo así, la operación de la extracción de la información del ambiente se configura como una actividad de tipo exploratorio que, a través de ojeadas sucesivas no aleatorias (dirigidas a la parte más informativa de la escena o imagen), permite componer un esquema integrado que contenga la globalidad de dicha escena o imagen.

Por tanto, el modo cómo una persona mira el mundo depende tanto de su conocimiento de éste como de sus objetivos; es decir, de la información que busca. Es precisamente esa búsqueda la causa de que cada movimiento ocular verifique una expectativa, y lo que percibimos de una escena sea el mapa que hemos ido recomponiendo activamente mediante el ensamblaje de fragmentos más pequeños. Si no fuéramos capaces de producir ese mapa mental, apenas tendríamos otra cosa: imágenes momentáneas desorganizadas y discontinuas.

La imagen no transmite un sentido, sino que tiene sentido en sí misma, dependiendo del observador, de lo que éste es; es decir, el contexto social influye en la percepción del observador.

Desde el momento en que la percepción se concibe como un proceso activo en el que se implica la globalidad de la persona, no puede dejarse de lado la relación existente entre los elementos cognitivos planteados por el sujeto y el modo en que éstos se ejercen. Porque en todo acto perceptivo se involucra el sujeto perceptor en tanto que animal histórico cultural. Presente, pasado, futuro, como proyecto, deseos, intenciones inconscientes, todo viene a configurar el plan perceptivo. 
Las percepciones dependen de los contextos culturales en los que se mueve el perceptor: las representaciones que se hacen de las cosas podrían ser el resultado de las experiencias previas que ha tenido sea en el ámbito de las imágenes, el color o las formas.

Así, por ejemplo, las culturas indígenas manifiestan una experiencia perceptiva más abarcadora, porque su mundo visual y su campo visual tienen puntos de confluencia más fuertes que los que podría tener un perceptor de otra cultura.

\section{La experiencia de CEFOCINE}

El Centro de Formación Cinematográfica para Niños nació en Quito, Ecuador, en 1989, y continúa hasta la actualidad como una respuesta a las necesidades de sistematización y planificación de nuevas teorías y prácticas en el trabajo pedagógico con niños mediante el recurso audiovisual. El trabajo del Centro partió de la recolección de datos sobre actividades desarrolladas por algunos grupos vinculados con la Cinemateca Nacional a favor de los niños, en tanto tenía que ver con el uso de medios de educación para el arte.

La actividad del Centro es un espacio alternativo pedagógico que, basado en una nueva práctica educativa comunicacional, busca hacer procesos de alfabetización de la imagen utilizando el Lenguaje Total como metodología y a los medios de comunicación como herramientas del proceso, ejercitando en todas sus etapas y en todos los productos elaborados por los niños, jóvenes, docentes y padres de familia, la escritura y la expresión artística. 
Los objetivos del Centro son:

- Sensibilizar al niño frente a la imagen cinematográfica y televisiva desde una educación de la percepción.

- Desmitificar los medios de comunicación social para permitir que el niño sea el gestor de sus propias imágenes.

- Orientar el trabajo de los docentes hacia la aplicación del Lenguaje Total como metodología.

- Difundir conocimientos esenciales sobre comunicación y lenguaje audiovisual a padres de familia.

- Promover la producción de materiales audiovisuales por los niños y las niñas participantes de los talleres.

No se transmiten conocimientos, se ensanchan las posibilidades perceptivas para que, además de percibir los estímulos, sean interpretados y decodificados. La experiencia lleva a leer otros signos que no son los lingüísticos y a expresarse a través de ellos.

En los talleres, los niños expresan su mundo en un ambiente de libertad; su actividad es un compromiso voluntario en el cual su participación se caracteriza por la espontánea dosis de emotividad expuesta. Ellos se valen de palabras, sonidos e imágenes para expresarse y realizarse: lenguaje total plenamente humano, que al calor del grupo permite mediar entre la educación para el individualismo esterilizante y el colectivismo creador y constructor.

La metodología aplicada en los talleres con los niños ha tomado como aspecto importante la resignificación como un aporte de la teoría activa y creativa, según la cual el sujeto relaciona el mensaje recibido con su pro- 
pia identidad y contexto social. El proceso educativo de la propuesta activo-creativa es similar a la crítica-problematizadora, en el sentido de ver la educación como un proceso que parte de una experiencia, se dialoga sobre ella, se interpreta, se generaliza y se aplica a la vida. La educación se ve como un proceso permanente en el que los sujetos van descubriendo, elaborando, reinventando y proponiendo desde las expresiones artísticas que conlleva el mundo de la imagen.

\section{Bibliografía}

APARICI, Roberto

1989 Imagen, video y educación. México: Fondo Cultura Económica. 1989.

BELLARMINO, Roberto

1996 Desafíos valóricos para la educación siglo XXI. Santiago de Chile.

CABRERA, Ramón

1991 Apreciación de las Artes Visuales. La Habana: ed. Pueblo y Educación.

CORONADO, Carmita

1999 Tesis de Maestría Propuesta Metodológica de lectura crítica, sistematización experiencia de CEFOCINE. Pontificia Universidad Católica del Ecuador.

DAZA, Gladys

1990 Cultura de la Imagen, orientación educativa. Bogotá: ed. CEDAL.

DELORS, Jacques

1996 La educación encierra un tesoro: ed. UNESCO.

DOMÍNGUEZ, María Josefa

1990 Activos y creativos con los medios de comunicación. Bogotá: UNESCO.

GUBERN, Román

1983 La imagen y la cultura de masas. Barcelona: ed. Bruguera. FUENZALIDA, Valerio

1991 Educación para la Televisión en América Latina, Santiago de Chile. CENECA. 
MASTERMAN, Len

1993 La enseñanza de los medios de comunicación. Madrid: ed. De la Torre.

OROZCO, Guillermo

1990 Educación para la recepción. México: ed. Trillas.

OLIVEIRA, Ismar de

1984 Comunicao Educao, Sao Paulo: ed. Moderna.

SARTORI, Giovanni

1998 Homo Videns, la sociedad teledirigida, Buenos Aires: ed. Taurus.

SILVERSTONE, Roger

1996 Televisión y vida cotidiana. Londres: ed. Amorrortu.

UNESCO

1989 Recepción activa, niños y medios de comunicación social. Bogotá. 